Review Article

\title{
The Potential Therapeutic Role of Mesenchymal Stem Cells-Derived Exosomes in Osteoradionecrosis
}

\author{
Yuetian Li $\mathbb{D},{ }^{1}$ Xinyue Wang $\mathbb{D},{ }^{1}$ Yu Pang $\mathbb{D}^{1},{ }^{1}$ Shuangcheng Wang $\mathbb{D}^{1},{ }^{1}$ Meng Luo $\mathbb{D}{ }^{1}$ \\ and Bo Huang $\mathbb{D}^{2}$ \\ ${ }^{1}$ West China School of Stomatology, Sichuan University, Chengdu 610041, China \\ ${ }^{2}$ State Key Laboratory of Oral Diseases, and General Dentistry, West China Hospital of Stomatology, Sichuan University, \\ Chengdu 610041, China
}

Correspondence should be addressed to Bo Huang; hbxx8818@126.com

Received 25 September 2021; Revised 7 November 2021; Accepted 12 November 2021; Published 2 December 2021

Academic Editor: Feng Jiang

Copyright (c) 2021 Yuetian Li et al. This is an open access article distributed under the Creative Commons Attribution License, which permits unrestricted use, distribution, and reproduction in any medium, provided the original work is properly cited.

As one of the most serious complications of radiotherapy, osteoradionecrosis (ORN) seriously affects the quality of life of patients and even leads to death. Vascular injury and immune disorders are the main causes of bone lesions. The traditional conservative treatment of ORN has a low cure rate and high recurrent. Exosomes are a type of extracellular bilayer lipid vesicles secreted by almost all cell types. It contains cytokines, proteins, mRNA, miRNA, and other bioactive cargos, which contribute to several distinct processes. The favorable biological functions of mesenchymal stem cells-derived exosomes (MSC exosomes) include angiogenesis, immunomodulation, bone regeneration, and ferroptosis regulation. Exploring the characteristic of ORN and MSC exosomes can promote bone regeneration therapies. In this review, we summarized the current knowledge of ORN and MSC exosomes and highlighted the potential application of MSC exosomes in ORN treatment.

\section{Introduction}

Osteoradionecrosis (ORN) is regarded as the most destructive complication of radiotherapy $[1,2]$, which mainly manifests as chronic spontaneous pain, dysphagia, facial deformation, and other symptoms [3]. It seriously affects the quality of life of patients and even leads to death [4]. The first clinical evidence of ORN radiotherapy was reported in 1922 [5]. Using modern treatment techniques, such as intensity-modulated proton therapy, the estimated incidence of ORN has dropped to $2-5 \%$ [6-10]. However, ORN has the highest incidence in oral cancer radiotherapy, as high as $78 \%$ [11]. The incidence of the mandibular is significantly higher than that of the maxilla, mainly due to the higher blood supply of the upper jaw bone [12]. ORN is irreversible and can last for decades. However, there is still no gold standard treatment or consensus guidelines.

Exosomes belong to a category of extracellular vesicles, with a diameter of $40-160 \mathrm{~nm}$ (an average of $100 \mathrm{~nm}$ ) [13] and a density of $1.13-1.19 \mathrm{~g} / \mathrm{ml}$ [14]. They are membranebounded phospholipid vesicles with a cup-shaped structure derived by all eukaryotic cells $[15,16]$ (Figure 1). These cells secrete exosomes through regulatory processes such as endocytosis, fusion, and efflux [17].

There are surface markers on the exosome membrane, such as CD63 [18-21], CD9, CD81 [22], and other transmembrane proteins. Exosomes contain many bioactive cargos, including cytokines, lipids, mRNAs, and more than 170 miRNAs and 304 proteins [13]. The contents of exosomes change dynamically and are related to the cell type and state. Recipient cells can take up the exosomes through diverse markers on the membrane to perform different functions [13]. Due to the rich sources, simplicity, safe, low immunogenicity, and other advantages, exosomes have become a hot spot in current research studies [23-27].

Among the potential providers of exosomes, such as epithelial cells [28], mast cells [29], dendritic cells [30], lymphocytes [31-33], and neuronal cells [34], mesenchymal stem cells (MSCs) have been widely concerned as seed cells in the field of tissue engineering and regenerative medicine. MSC exosomes are the primary product of MSCs 

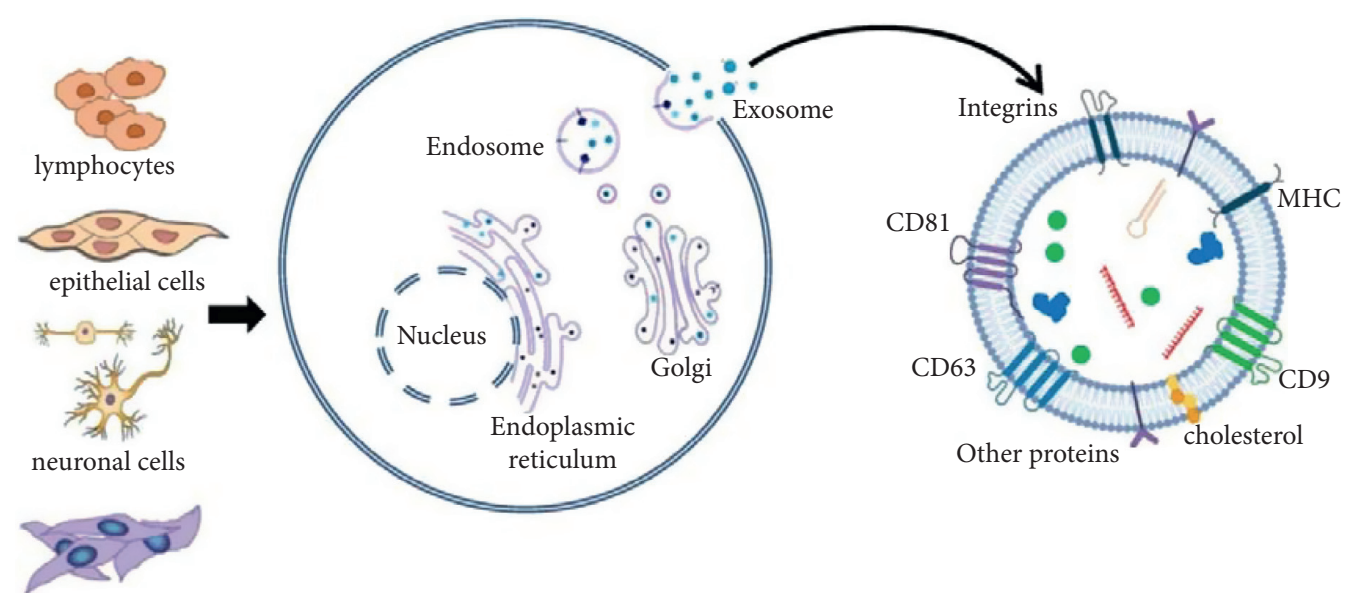

mesenchymal stem cells

(a)

(b)

(c)

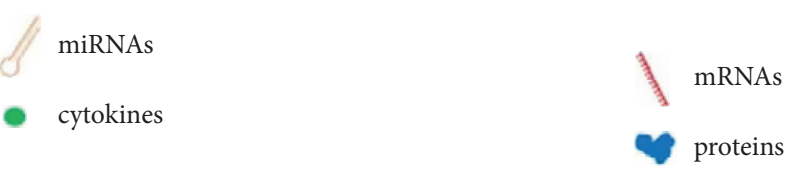

Figure 1: Characteristics of exosomes. (a) Exosomes derived from almost all types of cells. (b) Exosomes originating from an endocytic compartment and secreted from intracellular endosomes into extracellular space. (c) Exosomes are vesicles with a phospholipid bilayer membrane. The exosomes contain some biomarkers, such as CD9, CD63, CD81, and integrins, MHC, cholesterol, and other proteins on the surface. The exosomes also contain miRNAs, mRNAs, cytokines, and some proteins in the lumen. MHC, major histocompatibility complex.

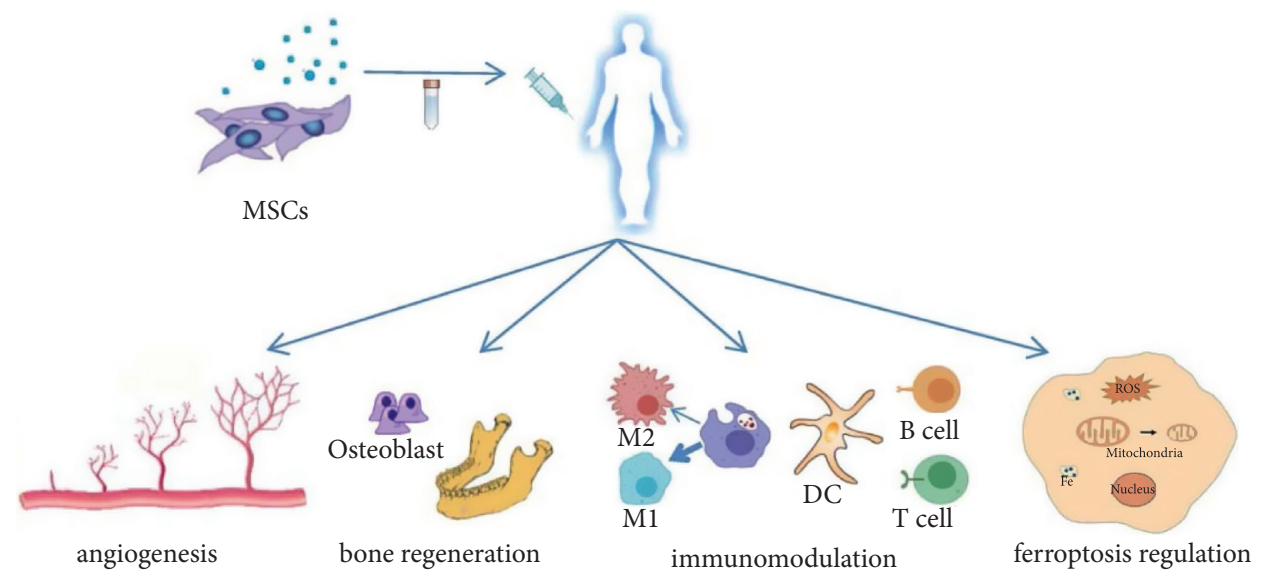

FIgURE 2: Therapeutic effects of MSC exosomes on ORN. Exosomes isolated from MSC and transferred to body. MSC exosomes exert their therapeutic effects on ORN through their angiogenesis, immune regulation, bone regeneration, and iron death regulation abilities.

[35]. Retaining similar biological characteristics and functions as MSCs, MSC exosomes are more stable and easier to preserve [36]. According to a report, MSC exosomes have enormous potency in repairing tissue lesions. They can promote the repair of damaged endometrium in intrauterine adhesion through the TGF- $\beta 1 /$ Smad pathway [25]. They can change the immune environment to promote myocardial repair [37]. They can also promote skin regeneration and wound healing by accelerating angiogenesis, fibroblast proliferation, and collagen deposition [38-40]. In diabetic rats, exosomes derived from MSCs pretreated with atorvastatin can accelerate wound repair by promoting angiogenesis via the AKT/eNOS pathway [41].
MSC exosomes have the ability of angiogenesis, immunomodulation, bone regeneration, and ferroptosis regulation, which provides novel insight for the treatment of ORN (Figure 2). Therefore, this review will discuss the latest pathogenesis of ORN and the therapeutic mechanism of MSC exosomes. We also discuss the advantages and challenges of exosomes' clinical application.

\section{Pathophysiology of ORN}

ORN refers to the bones that cannot heal for more than three months and have no persistent tumors after being irradiated $[42,43]$. Clinical signs and symptoms vary with the stage of 
ORN, including mucosa ulceration and necrosis [44], trismus [45], and suppuration [46]. Pain, anesthesia, halitosis, and dysgeusia are neurological symptoms when ORN occurs in the oral [42]. With the development of ORN, it becomes difficult to speak, masticate, and even open mouth [47-49]. Radiography, computed tomography (CT) scans, and orthopantomogram (OPT) are recommended to detect ORN according to the degree of bone lesions (one of its most typical pathological changes) [5]. However, the characteristics of the image are uncorrelated with the severity of ORN [50].

To clarify the pathogenesis of ORN, different scholars have proposed different hypotheses [51-56]. The first is the radiotherapy-trauma-infection theory [51], in which bacteria invade the jaw bone through the wound, cause chronic infection disease, and lead to ORN [48]. It was the basis of the popular antibiotic therapy for ORN. However, this theory had been questioned because no microorganisms had been found in deep lesions [52]. With the advancement of microbial detection technology, the presence of the deep microorganisms in radionecrotic mandibles was detected by DNA hybridization, suggesting that the theory may still be reasonable, and the role of anaerobic infection in ORN may be essential [57].

The second is the three-hypo theory based on vascular injury and immune dysfunction. After radiation, the hypoxic, hypocellular, and hypovascular state in the bone leads to vascular injury and immune dysfunction, causing chronic nonhealing wounds and ORN [52]. This hypothesis was once considered to be the most likely to explain the ORN mechanism [58]. For decades, hyperbaric oxygen (HBO) therapy based on it has been the standard and conservative choice for the treatment of ORN [59]. However, the development of HBO therapy based on this three-hypo hypothesis is still controversial [60-62]. Annane et al. demonstrated that patients with overt mandibular ORN did not benefit from HBO therapy in a randomized, doubleblind, and placebo-controlled trial [61]. Forner et al. found that only minor stem cells were mobilized in head and neck irradiated patients treated with HBO [62]. Since there are few studies on postoperative radiotherapy for head and neck cancer, the effect of $\mathrm{HBO}$ on ORN and its specific mechanisms need to be further explored.

The third is the reactive oxygen species (ROS) theory, in which ROS caused endothelial cell damage in ORN $[53,63]$. The occurrence of ORN was related to the ischemia caused by vascular embolism $[54,55]$ and the imbalance of bone regeneration caused by hypovascularity [64]. In addition, some studies have suggested that the radiation injury of osteoclasts occurs earlier than vascular changes, which may be the initial event in the development of ORN [48, 65-67].

The fourth is the mainstream radiation-induced fibroatrophic theory, in which the pathogenesis of ORN is divided into three stages. The first stage is the initial prefibrotic stage. Radiation-induced ROS and chemokines attract leukocytes to the injury sites, triggering an acute inflammatory response through ROS produced from macrophage and leading to endothelial cell damage $[5,63,68]$. The next stage is the constitutive organized stage. Due to the loss of the vascular endothelial barrier, cytokines such as FGF- $\beta$, TGF- $\beta 1$, tumor necrosis factor- $\alpha$ (TNF- $\alpha$ ), and interleukins (IL) result in the accumulation of fibroblasts and transdifferentiation of fibroblasts into myofibroblasts (MFB) [69-71]; The last stage is the late fibroatrophic stage. Hypoxic, hypocellular, and hypovascular environments can lead to bone fragility, and changes in the local metabolic environment can lead to ORN [53]. The key factor of this theory is the generation of MFB [72]. MFB proliferates rapidly and produces a large amount of extracellular matrix protein and collagen, which disrupts the balance of synthesis and degradation in the radiated tissue. As a result, fibrous tissue replaces the bone matrix, leading to the occurrence of ORN. In the meantime, the combination of pentoxifylline (PTX) and vitamin E for antioxidation and antifibrosis therapy has shown efficacy in clinical trials [73-76], which points out the direction for exploring new therapies.

Recently, ferroptosis has been discovered as an irondependent form of nonapoptotic cell death, providing a new possible theory for ORN $[56,77,78]$. Triggered by excessive lipid peroxidation, ferroptosis has morphological, biochemical, and genetic characteristics different from apoptosis $[79,80]$. One of its representative characteristics is smaller mitochondria with condensed mitochondrial membrane densities [81]. During radiotherapy, ionizing radiation generates ROS and induces the expression of longchain acyl-CoA synthetases 4 (a lipid metabolism enzyme), which leads to lipid peroxidation and ferroptosis [82]. In cancer cases, some small molecules promote ferroptosis and inhibit tumor cells by synergizing with radiation and inhibiting glutathione peroxidase 4 [83]. However, excessive ferroptosis also occur in normal cells, ischemia-reperfusion injury, kidney failure, neurodegeneration, and other diseases [56]. If ferroptosis occurs in the osteoblasts, osteoporosis and osteonecrosis will appear [84]. Exosomes derived from mouse vascular endothelial cells can reverse osteoporosis by inhibiting osteoblast ferroptosis [84]. However, there are insufficient clinical trials and basic experiments to prove the relationship between ferroptosis and ORN.

\section{Traditional Treatments of ORNs}

Based on the degree of bone and soft tissue damage, ORN consists of four stages (stage 0 , stage I, stage II, and stage III) [60]. Different stages of ORN require distinct treatment protocols [85].

Surgical treatment has been widely used in ORN. Surgery includes removal of small sequestrum, ostectomy, radical resection, and flap reconstruction [85]. According to a review, the most common option for mandible reconstruction was a fibula-free flap with plenty of vessels to provide sufficient blood supply [86]. However, its relatively large wound and slow recovery are serious shortcomings.

In addition to surgery, there are six types of conservative therapies for ORN. They are debridement, HBO therapy, PTX and tocopherol (vitamin E), chlorhexidine, ultrasound therapy, growth factor, and MSC therapy. However, each of them has its shortcomings and can only be combined with other treatments. 
TABLE 1: MSC exosomes promote angiogenesis through various signaling pathways.

\begin{tabular}{|c|c|c|c|c|}
\hline Exosomes & $\begin{array}{l}\text { Pathway/key } \\
\text { molecule }\end{array}$ & Function & $\begin{array}{l}\text { Experiment } \\
\text { type }\end{array}$ & Reference \\
\hline $\begin{array}{l}\text { MSC exosomes derived from } \\
\text { overexpressing HIF- } 1 \alpha\end{array}$ & Jagged $1 /$ Notch & $\begin{array}{l}\text { Enhanced angiogenesis and capillary-like tube } \\
\text { formation }\end{array}$ & In vitro & {$[111]$} \\
\hline $\begin{array}{l}\text { Exosomes derived from DMOG- } \\
\text { stimulated human bone marrow MSCs }\end{array}$ & Akt/mTOR & $\begin{array}{c}\text { Promoted angiogenesis in the critical-sized } \\
\text { calvarial defect rat model }\end{array}$ & In vivo & [112] \\
\hline iPS-MSC-Exos & $\mathrm{PI} 3 \mathrm{~K} / \mathrm{Akt}$ & $\begin{array}{l}\text { Enhanced the proliferation, migration, and tube- } \\
\text { forming capacities of endothelial cells }\end{array}$ & In vitro & {$[113]$} \\
\hline Exosomes from hiPSC-MSC & - & $\begin{array}{c}\text { Enhanced angiogenesis and osteogenesis under } \\
\text { osteoporotic conditions }\end{array}$ & In vivo & {$[114]$} \\
\hline $\begin{array}{l}\mathrm{CD}^{+} 3^{+} \text {exosomes derived from bone } \\
\text { marrow MSCs }\end{array}$ & Wnt3 protein & Enhanced endothelial angiogenesis & In vitro & {$[115]$} \\
\hline $\begin{array}{l}\text { Exosomes released from hP-MSCs by NO } \\
\text { stimulation }\end{array}$ & $\begin{array}{l}\text { VEGF and } \\
\text { miR-126 }\end{array}$ & Enhanced the angiogenic effects of HUVECs & In vitro & {$[116]$} \\
\hline
\end{tabular}

Eliminating all bones that are no longer vascularized can prevent long-term infection and inflammation, thereby facilitating subsequent therapies [87]. According to recent evidence, $\mathrm{HBO}$ therapy was not recommended for ORN at any stage [61, 62, 88, 89]. PTX and vitamin E can prevent radiation-induced fibrosis (RIF) in patients with ORN through a synergistic effect [90-92]. A phase II trial showed that PTX, tocopherol, and clodronate (together referred to as PENTOCLO) helped $89 \%$ of patients to recover within 14 months [93]. Although PENTOCLO has a positive impact on the treatment of early ORN, stage II and III cases require surgery for assistance [94]. Chlorhexidine is a commonly used drug for the treatment of ORN since it can prevent infection and promote wound healing [95]. Chlorhexidine can be used as a bactericide against Gram-positive and Gram-negative microorganisms and some yeasts [96]. A study showed that with curettage and $0.12 \%$ chlorhexidine flushing as the main treatment, exposed bone closure occurred in $50 \%$ of cases, confirming the clinical effectiveness of chlorhexidine [97]. Ultrasound therapy can promote angiogenesis for revascularization of ORN [98-100]. However, due to the lack of further research, therapeutic ultrasound can only be used as an experimental option in clinical trials [85]. Due to its ability to regulate cytokines, growth factors and MSC therapy are other potential choices [85]. The plasma with growth factors-Endoret is beneficial to the vascularization and epithelialization of ORN [101]. The combination of rat MSCs and bone morphogenetic protein2 (BMP2) is effective in the ORN treatment [102]. This feature of MSCs provides evidence for the potential therapeutic capability of the exosomes derived from MSCs.

Although conservative therapies can treat some early ORN, the cure rate is only $28.6 \%$, combined surgery is required to obtain better effects, and the recurrence is possible [103]. Therefore, it is necessary to study a new treatment.

\section{Therapeutic Effects of MSC Exosomes on ORN}

4.1. Angiogenesis. Angiogenesis and vascularization play important roles in bone regeneration after radiation. Promoted by a variety of endogenous proangiogenic factors, including vascular endothelial growth factor (VEGF), hepatocyte growth factor (HGF), stromal-derived factor-1 (SDF-1), platelet-derived growth factor (PDGF), fibroblast growth factor (FGF), and epidermal growth factor (EGF) [104, 105], endothelial cells successively form buds, capillaries, and vessel networks [36]. Exosomes loaded with miRNA-7b, -9, -21, -26a, -27a, -210, -378, -195-497 cluster, $-675-126$ [106], -132 [107], -135b-5p, and -499a-3p show positive effects on angiogenesis [106-110]. Further studies have shown that the noncoding RNA cargos play essential roles in regulating angiogenesis by accommodating proangiogenic factors.

Recent studies have revealed that MSC exosomes with different contents can promote angiogenesis through various signaling pathways (Table 1). Exosomes secreted by MSC enhance angiogenesis through the Jagged 1 and Notch signaling pathway under the stimulation of hypoxia-inducible factor-1 $\alpha$ (HIF-1 $\alpha)$ [111]. Exosomes secreted by human bone marrow MSCs promote angiogenesis through the Akt/mTOR signaling pathway under the stimulation of dimethyloxalylglycine (DMOG) [112]. Exosomes secreted by human-induced pluripotent stem cells (hiPSC-MSC) enhance angiogenesis through the PI3K/Akt signaling pathway in endothelial cells $[113,114]$. $\mathrm{CD}^{+} 3^{+}$exosomes secreted by bone marrow MSCs transported Wnt3 protein exteriorly to enhance angiogenesis [115]. Exosomes secreted by human placenta-derived MSCs (hP-MSCs) can enhance the angiogenic effects of HUVECs through increasing VEGF and miR-126 under the stimulation of nitric oxide (NO) [116].

The vascular injury through different mechanisms can also be prevented or even reversed by MSC exosomes. Exosomes play a key role in repairing DNA double-strand breaks and alleviating oxidative damage [117]. After exposure to MSC exosomes, the apoptosis caused by radiation-induced DNA damage in vascular endothelial cells is reduced [118].

4.2. Immunomodulation. According to the radiation-induced fibroatrophic theory, radiation-induced endothelial injury leads to necrosis and tissue ischemia in the prefibrotic stage and constitutive organized stage [53]. The released free radicals and chemokines attract white blood cells to the injury site and cause inflammation [68]. 
Since the immune disorder is one of the pathogeneses of ORN, MSC exosomes may become a potential treatment for ORN due to their immunomodulation capability in bone and cartilage tissue [36]. MSC exosomes exert kinds of anti-inflammatory function through immunomodulation [119-122]. First, MSC exosomes induce macrophages to shift from the M1-like to the M2-like phenotype [123]. The former is a classic proinflammatory cell type, and the latter is known for its anti-inflammatory responses [124, 125]. Exosomal miRNA-146 [123], miRNA-34 [126], and miRNA-181a $[127,128]$ can reduce the M1-related cytokines, such as IL-6, IL-12, and TNF- $\alpha$, and enhance the M2-related cytokines, such as IL-10 and TGF- $\beta$, by promoting M2 polarization of macrophages [129, 130]. MSC exosomes also play the immunoregulatory role on osteogenesis by decreasing M1 phenotype markers of macrophage [131]. MSC exosomes loading with Wnt could activate $\mathrm{Wnt} / \beta$-catenin signaling on target cells and alleviate radiation-induced bone loss [132]. Wnt $/ \beta$-catenin signaling has been implicated in M2 macrophage polarization [133]. Second, MSC exosomes transport metallothionein-2, which causes inflammation reduction in a macrophage-dependent mechanism [129], participates in NO-mediated osteogenic pathways in osteoblasts [134]. Third, MSC exosomes mediate the acquisition of an immune tolerogenic phenotype in mature dendritic cells (DCs) [135]. Then, the tolerogenic DCs promote naïve $\mathrm{CD}^{+}{ }^{+} \mathrm{T}$ cells to differentiate into Treg cells by secreting a variety of anti-inflammatory factors [135]. Fourth, MSC exosomes decrease lymphocyte proliferation [135] and serve as conveyors of the immunosuppressive effect on $B$ lymphocytes [136]. In addition, the number of $\mathrm{CD} 8^{+}$ T cells and the ratio of $\mathrm{CD}^{+} \mathrm{T}$ cells to $\mathrm{CD} 4^{+} \mathrm{T}$ cells in the peripheral blood were both restricted in certain conditions [137].

Some studies have proved the anti-inflammatory effects of MSC exosomes in bone and cartilage tissues [138-140]. Exosomes derived from adipose-derived MSCs can reduce the production of inflammatory mediators, such as TNF- $\alpha$, IL-6, PGE2, and NO, to alleviate joint osteoarthritis (OA) [138]. Exosomes derived from human bone marrow MSCs can promote cartilage regeneration by inhibiting TNF$\alpha$-related collagenase activity [139]. They can also inhibit macrophage activation and chondrocytes apoptosis to treat joint damage [140].

To our knowledge, TGF- $\beta 1$ and ROS are thought to play a more important role in radiation-induced fibrosis [141-144]. ROS can upregulate the expression of several fibrogenic genes by activating HIF- $1 \alpha$ and releasing TGF- $\beta 1$ [145]. It seems that we could come to reasonable speculation. MSC exosomes may slow down the fibrosis process in ORN development through immunoregulation. However, these conjectures require further study to confirm.

4.3. Bone Regeneration. Osteoblasts (OBs), derived from MSCs, account for $4-6 \%$ of osteocytes. The main function of OBs is to deposit calcium salts and form the bone. MSC exosomes can regulate the osteogenic differentiation of
MSCs and the proliferation of OBs by using miRNAs to affect the expression of OBs-related mRNAs [146] (Table 2).

MSC exosomes containing miR-29a and miR-29c induce the osteogenic differentiation of MSCs by increasing the expression of OBs-related miRNAs, such as miR-206, miR-196a, and miR-27a [147]. At different time points of the osteogenic differentiation of MSCs, the expression of miR-199b, miR-218, miR-148a, and miR-135b increased, and the expression of miR-221, miR-155, miR-885-5p, miR-181a, and miR320 decreased in MSC exosomes [149]. The differential expression of let-7, miR-218, miR-196a, and miR-118a in MSC exosomes can also stimulate MSCs to differentiate into osteoblasts [148]. Studies have found that miR-885-5p regulates BMP2-induced osteogenic differentiation $[149,159]$. MSC exosomes also promote the proliferation of OBs through miR-122-5p and the MAPK signaling pathway $[160,161]$. Some contents of MSC exosomes, such as miR-92a-3p and miR-140-5p, can alleviate $\mathrm{OA}$ by promoting chondrogenesis, enhancing chondrocytes migration, and suppressing cartilage degradation $[157,158]$.

In addition, MSC exosomes can promote the proliferation of bone marrow stem cells and reduce radiation damage by reducing cell apoptosis and DNA damage [162]. Transplantation of human MSCs can enhance mouse bone marrow production and megakaryocyte production [163]. Injection of MSC exosomes can protect cd $92 / 2$ mice from delayed fracture healing [164]. The miR-148a-3p in MSC exosomes can prevent the osteonecrosis of the femoral head by inhibiting the expression of Smad ubiquitination regulatory factor 1 (SMURF1) [151].

4.4. Ferroptosis Regulation. Ferroptosis is an iron-dependent form of nonapoptotic cell death and is a newly discovered potential mechanism for tumors treatment $[56,77,78]$. If there is pathological ferroptosis in OBs, osteoporosis and osteonecrosis will occur [84]. The release of iron from exosomes mediates ferroptosis resistance [165]. Prominin-2 is a lipid dynamics regulation protein. It promotes the formation of multivesicular bodies (MVBs) and exosomes containing ferritin, thereby transporting iron out of cells and preventing ferroptosis $[166,167]$. Given that exosomes are involved in the ferroptosis resistance in tumor cells [168], they may alleviate ORN by affecting the ferroptosis resistance in osteogenesis-related cells. MSC exosomes have high biocompatibility and efficiency $[169,170]$. This characteristic may provide a novel idea for improving ORN by regulating ferroptosis.

4.5. Exosomes and Tumor Radiotherapy. Many studies have shown that exosomes are closely related to tumor radiotherapy. Exosomes derived from MSCs increase the inhibitory effect of radiotherapy on tumor metastasis [171]. In prostatic cancer, exosomes mediate radiation-induced nontargeting effects [172]. Radiation-activated p53 can be transmitted away through exosomes [173, 174]. Breast cancer exosomes promote DNA damage repair responses after radiation by regulating the phosphorylation of 
TABLE 2: The expression of partial miRNA derived from exosomes and the effects on osteogenesis.

\begin{tabular}{lc}
\hline mi-RNA & Expression level \\
\hline miR-29a & Carried in MSC exosomes \\
miR-29c & The expression of osteoblast-related miRNA was \\
miR-206 & significantly increased [147] \\
miR-27a & \\
miR-196a & BMSCs culture [149] \\
miR-218 & Significantly upregulated in exosomes isolated from \\
miR- & \\
199b-5p & \\
miR- & \\
148a-3p & \\
miR-135b & \\
miR-221 & Significantly lower expressed in individual exosomal \\
miR-155 & samples over time [149] \\
miR- & \\
181a-3p & \\
miR-320c & \\
miR-885- & \\
$5 p$ & \\
miR-92a- & Reduced in the OA chondrocyte-secreted exosome \\
3p & \\
miR-140- & Derived from miR-140-5p-overexpressing synovial \\
$5 p$ & mesenchymal stem cells [158] \\
\hline
\end{tabular}

Induce the osteogenic differentiation of MSCs [147]

Promote the proliferation and differentiation of OB [147]

Stimulate the differentiation of BMSCs into osteoblasts [148]

Stimulate the differentiation of BMSCs into osteoblasts [148]

Promote chondrogenic differentiation [150]

Prevent the osteonecrosis of the femoral head by inhibiting SMURF1 [151]

Enhance chondrocyte proliferation by downregulating SP1 [152]

Inhibit osteogenic differentiation of BMSCs via the IGF-1/ERK pathway [153]

Suppress osteoblastic differentiation by targeting SIRT1 [154]

Inhibit osteogenic differentiation of MCSs by targeting BMP10 [155]

Reduce the osteogenic potential of BMSCs through Runx2 [156]

Exert a negative regulatory effect on the osteogenic differentiation of BMSCs by inhibiting Runx2 [149]

Promote chondrogenesis and suppress cartilage degradation [157]

Enhance proliferation and migration of chondrocytes through the Wnt signaling pathway [158]

checkpoint kinase 1 (Chk1) [175]. Since exosomes can increase radioresistance through the miRNA inside [176, 177], we speculate that MSC exosomes may alleviate ORN by increasing the radioresistance of healthy bone cells.

\section{Discussion}

The treatment plan of ORN is comprehensive according to patients' age, compliance, and hospital conditions. The basic principles should be formulated based on classification and stage [85].

Due to the subsequent high infection rate, HBO treatment is not the best option [178]. At present, the traditional method for the latter stage of ORN is surgery combined with conservative treatments [85]. Adjuvant drugs such as chlorhexidine [179], antibiotics [85], and analgesics [180] can only be in combination with other surgical treatments, such as removal of small sequestrum, marginal mandibulectomy, segmental mandibulectomy, radical resection, and flap reconstruction [85]. However, a simple and atraumatic method is needed to treat ORN. MSC exosomes are promising candidates for ORN therapy, mainly due to their unique biological properties and various physiological effects.

MSC exosomes have higher biocompatibility than MSCs and can easily avoid immune rejection when transferred to impaired tissues [181]. MSC exosomes can avoid their internal specific cytokines or miRNA from being degraded by enzymes and achieve a stable therapeutic effect [182]. MSC exosomes can simultaneously activate multiple signaling pathways, avoid genetic modification of target cells, and provide repeatable and predictable results with stable phenotypes [181]. MSC exosomes have many advantages over traditional bone grafting because they can combine with a variety of biomaterials to repair bone defects [183]. Based on the above advantages, MSC exosomes show beneficial prospects in the treatment of ORN.

However, the clinical application of MSC exosomes faces many challenges. First, due to the conditions for the production of exosomes, the contents of exosomes are relatively unstable [184]. For example, the miRNA profile of exosomes is significantly affected by ionizing radiation [185]. Second, there is no uniform standard for the identification, quantification, and purification of exosomes, which lead to diverse results in dose-dependent experiments and uncertain effects in clinical applications [36]. The International Society for Extracellular Vesicles (ISEV) recommended several methods for the separation of exosomes, such as differential centrifugation, size exclusion chromatography (SEC), immunoaffinity capture, and combinations of the above techniques [186]. However, the specific application scopes of each method still need to be illustrated and unified. Third, there is still a lack of methods to obtain high purity exosomes while ensuring sufficient yield. Studies suggested that culturing MSCs in scalable microcarrier-based three-dimensional cultures with tangential flow filtration can improve the productivity of MSC exosomes [187]. But more research studies are needed to translate this experiment discovery into clinical application. Finally, some roles of MSC exosomes remain unknown or inconsistent. Their various functions depend not only on the lipids, nucleic acids, and proteins inside but also on the molecules and particles on the surface [188]. Since only a small part of the roles has been explored, it is urgent to improve and innovate the research 
methods and to conduct in-depth research on contents and application methods of MSC exosomes.

\section{Conclusions}

Taken together, MSC exosomes play important roles in ORN through their ability to regulate angiogenesis, immunomodulation, bone regeneration, and ferroptosis. Although the clinical application of MSC exosomes faces many challenges, this promising field will still attract further explorations and provide a more theoretical basis and clinical treatment for ORN.

\section{Data Availability}

No data were used to support this study.

\section{Conflicts of Interest}

The authors declare that they have no conflicts of interest.

\section{Acknowledgments}

This work was supported by the National Outstanding Youth Science Fund Project of National Natural Science Foundation of China (82001090), Health Department of Sichuan Province (20PJ091), and Sichuan University Postdoctoral Interdisciplinary Innovation Startup Fund (20201105). The authors also thank the associate editor and the reviewers for their useful feedback that improved this study.

\section{References}

[1] F. Sulaiman, J. M. Huryn, and I. M. Zlotolow, "Dental extractions in the irradiated head and neck patient: a retrospective analysis of Memorial Sloan-Kettering cancer center protocols, criteria, and end results," Journal of Oral and Maxillofacial Surgery, vol. 61, no. 10, pp. 1123-1131, 2003.

[2] J. J. Thorn, H. S. Hansen, L. Specht, and L. Bastholt, "Osteoradionecrosis of the jaws: clinical characteristics and relation to the field of irradiation," Journal of Oral and Maxillofacial Surgery, vol. 58, no. 10, pp. 1088-1093, 2000.

[3] K. Katsura, K. Sasai, K. Sato, M. Saito, H. Hoshina, and T. Hayashi, "Relationship between oral health status and development of osteoradionecrosis of the mandible: a retrospective longitudinal study," Oral Surgery, Oral Medicine, Oral Pathology, Oral Radiology \& Endodontics, vol. 105, no. 6, pp. 731-738, 2008.

[4] R. E. Marx and R. P. Johnson, "Studies in the radiobiology of osteoradionecrosis and their clinical significance," Oral Surgery, Oral Medicine, Oral Pathology, vol. 64, no. 4, pp. 379-390, 1987.

[5] B. R. Chrcanovic, P. Reher, A. A. Sousa, and M. Harris, "Osteoradionecrosis of the jaws-a current overview-part 1," Oral and Maxillofacial Surgery, vol. 14, no. 1, pp. 3-16, 2010.

[6] D. H. Moon, S. H. Moon, K. Wang et al., "Incidence of, and risk factors for, mandibular osteoradionecrosis in patients with oral cavity and oropharynx cancers," Oral Oncology, vol. 72, pp. 98-103, 2017.

[7] A. A. Owosho, C. J. Tsai, R. S. Lee et al., "The prevalence and risk factors associated with osteoradionecrosis of the jaw in oral and oropharyngeal cancer patients treated with intensity-modulated radiation therapy (IMRT): the Memorial Sloan Kettering cancer center experience," Oral Oncology, vol. 64, pp. 44-51, 2017.

[8] S. Aarup-Kristensen, C. R. Hansen, L. Forner, C. Brink, J. G. Eriksen, and J. Johansen, "Osteoradionecrosis of the mandible after radiotherapy for head and neck cancer: risk factors and dose-volume correlations," Acta Oncologica, vol. 58, no. 10, pp. 1373-1377, 2019.

[9] J.-A. Chen, C.-C. Wang, Y.-K. Wong et al., "Osteoradionecrosis of mandible bone in patients with oral cancerassociated factors and treatment outcomes," Head \& Neck, vol. 38, no. 5, pp. 762-768, 2016.

[10] T. D. Maesschalck, N. Dulguerov, F. Caparrotti et al., "Comparison of the incidence of osteoradionecrosis with conventional radiotherapy and intensity-modulated radiotherapy," Head \& Neck, vol. 38, no. 11, pp. 1695-1702, 2016.

[11] M. M. Curi and L. Lauria, "Osteoradionecrosis of the jaws: a retrospective study of the background factors and treatment in 104 cases," Journal of Oral and Maxillofacial Surgery, vol. 55, no. 6, pp. 540-544, 1997.

[12] R. B. Morrish Jr., E. Chan, S. Silverman, J. Meyer, K. K. Fu, and D. Greenspan, "Osteonecrosis in patients irradiated for head and neck carcinoma," Cancer, vol. 47, no. 8, pp. 1980-1983, 1981.

[13] R. Kalluri and V. S. LeBleu, "The biology, function, and biomedical applications of exosomes," Science, vol. 367, no. $6478,2020$.

[14] X. O. Breakefield, R. M. Frederickson, and R. J. Simpson, "Gesicles: microvesicle "cookies" for transient information transfer between cells," Molecular Therapy, vol. 19, no. 9, pp. 1574-1576, 2011.

[15] M. Colombo, G. Raposo, and C. Théry, "Biogenesis, secretion, and intercellular interactions of exosomes and other extracellular vesicles," Annual Review of Cell and Developmental Biology, vol. 30, no. 1, pp. 255-289, 2014.

[16] G. Raposo and W. Stoorvogel, "Extracellular vesicles: exosomes, microvesicles, and friends," Journal of Cell Biology, vol. 200, no. 4, pp. 373-383, 2013.

[17] Y. Liu, Y. Wang, Q. Lv, and X. Li, "Exosomes: from garbage bins to translational medicine," International Journal of Pharmaceutics, vol. 583, Article ID 119333, 2020.

[18] A. V. Vlassov, S. Magdaleno, R. Setterquist, and R. Conrad, "Exosomes: current knowledge of their composition, biological functions, and diagnostic and therapeutic potentials," Biochimica et Biophysica Acta (BBA)-General Subjects, vol. 1820, no. 7, pp. 940-948, 2012.

[19] J. Lötvall, A. F. Hill, F. Hochberg et al., "Minimal experimental requirements for definition of extracellular vesicles and their functions: a position statement from the International Society for Extracellular Vesicles," Journal of Extracellular Vesicles, vol. 3, Article ID 26913, 2014.

[20] J. R. Edgar, E. R. Eden, and C. E. Futter, "Hrs- and CD63dependent competing mechanisms make different sized endosomal intraluminal vesicles," Traffic, vol. 15, no. 2, pp. 197-211, 2014.

[21] L. Chen, R. Chen, S. Kemper, and D. R. Brigstock, "Pathways of production and delivery of hepatocyte exosomes," Journal of Cell Communication and Signaling, vol. 12, no. 1, pp. 343-357, 2018.

[22] A. Zlotogorski-Hurvitz, D. Dayan, G. Chaushu, T. Salo, and M. Vered, "Morphological and molecular features of oral fluid-derived exosomes: oral cancer patients versus healthy 
individuals," Journal of Cancer Research and Clinical Oncology, vol. 142, no. 1, pp. 101-110, 2016.

[23] D. H. Ha, H. K. Kim, J. Lee et al., "Mesenchymal stem/ stromal cell-derived exosomes for immunomodulatory therapeutics and skin regeneration," Cells, vol. 9, no. 5, 2020.

[24] Z. Xunian and R. Kalluri, "Biology and therapeutic potential of mesenchymal stem cell-derived exosomes," Cancer Science, vol. 111, no. 9, pp. 3100-3110, 2020.

[25] G. Zhao, Y. Ge, C. Zhang et al., "Progress of mesenchymal stem cell-derived exosomes in tissue repair," Current Pharmaceutical Design, vol. 26, no. 17, pp. 2022-2037, 2020.

[26] K. Jayaramayya, I. Mahalaxmi, M. D. Subramaniam et al., "Immunomodulatory effect of mesenchymal stem cells and mesenchymal stem-cell-derived exosomes for COVID-19 treatment," BMB Reports, vol. 53, no. 8, pp. 400-412, 2020.

[27] T. Zhao, F. Sun, J. Liu et al., "Emerging role of mesenchymal stem cell-derived exosomes in regenerative medicine," Current Stem Cell Research and Therapy, vol. 14, no. 6, pp. 482-494, 2019.

[28] Y. Wang, Y. Shen, H. Liu et al., "Induction of inflammatory responses in splenocytes by exosomes released from intestinal epithelial cells following cryptosporidium parvum infection," Infection and Immunity, vol. 87, no. 4, 2019.

[29] G. Xie, H. Yang, X. Peng et al., "Mast cell exosomes can suppress allergic reactions by binding to IgE," The Journal of Allergy and Clinical Immunology, vol. 141, no. 2, pp. 788-791, 2018.

[30] M. Alexander, R. Hu, M. C. Runtsch et al., "Exosome-delivered microRNAs modulate the inflammatory response to endotoxin," Nature Communications, vol. 6, no. 1, p. 7321, 2015.

[31] S. C. Saunderson and A. D. McLellan, "Role of lymphocyte subsets in the immune response to primary B cell-derived exosomes," The Journal of Immunology, vol. 199, no. 7, pp. 2225-2235, 2017.

[32] V. Calvo and M. Izquierdo, "Inducible polarized secretion of exosomes in T and B lymphocytes," International Journal of Molecular Sciences, vol. 21, no. 7, 2020.

[33] J. Lu, J. Wu, J. Tian, and S. Wang, "Role of T cell-derived exosomes in immunoregulation," Immunologic Research, vol. 66 , no. 3, pp. 313-322, 2018.

[34] J. Fauré, G. Lachenal, M. Court et al., "Exosomes are released by cultured cortical neurones," Molecular and cellular neurosciences, vol. 31, no. 4, pp. 642-648, 2006.

[35] J. Q. Chen and L. H. Huang, "Advances of researchs on molecular mechanisms of mesenchymal stem cells and their exosomes in angiogenesis-review," Zhongguo Shi Yan Xue Ye Xue Za Zhi, vol. 26, no. 6, pp. 1858-1862, 2018.

[36] X. Pu, S. Ma, Y. Gao, T. Xu, P. Chang, and L. Dong, "Mesenchymal stem cell-derived exosomes: biological function and their therapeutic potential in radiation damage," Cells, vol. 10, no. 1, 2020.

[37] Y.-Y. Xiong, Z.-T. Gong, R.-J. Tang, and Y.-J. Yang, "The pivotal roles of exosomes derived from endogenous immune cells and exogenous stem cells in myocardial repair after acute myocardial infarction," Theranostics, vol. 11, no. 3, pp. 1046-1058, 2021.

[38] C. Wang, M. Wang, T. Xu et al., "Engineering bioactive selfhealing antibacterial exosomes hydrogel for promoting chronic diabetic wound healing and complete skin regeneration," Theranostics, vol. 9, no. 1, pp. 65-76, 2019.

[39] P. Wu, B. Zhang, H. Shi, H. Qian, and W. Xu, "MSC-exosome: a novel cell-free therapy for cutaneous regeneration," Cytotherapy, vol. 20, no. 3, pp. 291-301, 2018.
[40] W. Zhang, X. Bai, B. Zhao et al., "Cell-free therapy based on adipose tissue stem cell-derived exosomes promotes wound healing via the PI3K/Akt signaling pathway," Experimental Cell Research, vol. 370, no. 2, pp. 333-342, 2018.

[41] M. Yu, W. Liu, J. Li et al., "Exosomes derived from atorvastatin-pretreated MSC accelerate diabetic wound repair by enhancing angiogenesis via AKT/eNOS pathway," Stem Cell Research \& Therapy, vol. 11, no. 1, p. 350, 2020.

[42] A. Chronopoulos, T. Zarra, M. Ehrenfeld, and S. Otto, "Osteoradionecrosis of the jaws: definition, epidemiology, staging and clinical and radiological findings. A concise review," International Dental Journal, vol. 68, no. 1, pp. 22-30, 2018.

[43] M. S. Teng and N. D. Futran, "Osteoradionecrosis of the mandible," Current Opinion in Otolaryngology \& Head and Neck Surgery, vol. 13, no. 4, pp. 217-221, 2005.

[44] J. B. Epstein, F. L. W. Wong, and P. Stevenson-Moore, "Osteoradionecrosis: clinical experience and a proposal for classification," Journal of Oral and Maxillofacial Surgery, vol. 45 , no. 2, pp. 104-110, 1987.

[45] H.-K. Oh, M. S. Chambers, J. W. Martin, H.-J. Lim, and H.-J. Park, "Osteoradionecrosis of the mandible: treatment outcomes and factors influencing the progress of osteoradionecrosis," Journal of Oral and Maxillofacial Surgery, vol. 67, no. 7, pp. 1378-1386, 2009.

[46] A. R. Shaha, P. G. Cordeiro, D. A. Hidalgo et al., "Resection and immediate microvascular reconstruction in the management of osteoradionecrosis of the mandible," Head \& Neck, vol. 19, no. 5, pp. 406-411, 1997.

[47] T. Mücke, J. Koschinski, S. Wagenpfeil et al., "Functional outcome after different oncological interventions in head and neck cancer patients," Journal of Cancer Research and Clinical Oncology, vol. 138, no. 3, pp. 371-376, 2012.

[48] A. S. Jacobson, D. Buchbinder, K. Hu, and M. L. Urken, "Paradigm shifts in the management of osteoradionecrosis of the mandible," Oral Oncology, vol. 46, no. 11, pp. 795-801, 2010.

[49] T. Mücke, M. Konen, S. Wagenpfeil, M. R. Kesting, K. D. Wolff, and F. Hölzle, "Low-dose preoperative chemoradiation therapy compared with surgery alone with or without postoperative radiotherapy in patients with head and neck carcinoma," Annals of Surgical Oncology, vol. 18, no. 10, pp. 2739-2747, 2011.

[50] J. B. Epstein, F. L. Wong, A. Dickens, I. Szasz, and M. Lepawsky, "Bone and gallium scans in postradiotherapy osteonecrosis of the jaw," Head \& Neck, vol. 14, no. 4, pp. 288-292, 1992.

[51] I. Meyer, "Infectious diseases of the jaws," Journal of Oral Surgery, vol. 28, no. 1, pp. 17-26, 1970.

[52] R. E. Marx, "Osteoradionecrosis: a new concept of its pathophysiology," Journal of Oral and Maxillofacial Surgery, vol. 41, no. 5, pp. 283-288, 1983.

[53] S. Delanian and J.-L. Lefaix, "The radiation-induced fibroatrophic process: therapeutic perspective via the antioxidant pathway," Radiotherapy \& Oncology, vol. 73, no. 2, pp. 119-131, 2004.

[54] J. Bras, H. K. T. de Jonge, and J. P. R. van Merkesteyn, "Osteoradionecrosis of the mandible: pathogenesis," American Journal of Otolaryngology, vol. 11, no. 4, pp. 244-250, 1990.

[55] X. T. Xie, W. L. Qiu, W. H. Yuan, and Z. H. Wang, "Experimental study of radiation effect on the mandibular microvasculature of the Guinea pig," The Chinese Journal of Dental Research, vol. 1, no. 2, pp. 46-51, 1998. 
[56] B. R. Stockwell, J. P. Friedmann Angeli, H. Bayir et al., "Ferroptosis: a regulated cell death nexus linking metabolism, redox biology, and disease," Cell, vol. 171, no. 2, pp. 273-285, 2017.

[57] G. Støre, E. R. Eribe, and I. Olsen, "DNA-DNA hybridization demonstrates multiple bacteria in osteoradionecrosis," International Journal of Oral and Maxillofacial Surgery, vol. 34, no. 2, pp. 193-196, 2005.

[58] R. E. Marx, R. P. Johnson, and S. N. Kline, "Prevention of osteoradionecrosis: a randomized prospective clinical trial of hyperbaric oxygen versus penicillin," The Journal of the American Dental Association, vol. 111, no. 1, pp. 49-54, 1985.

[59] E. G. Mainous and G. B. Hart, "Osteoradionecrosis of the mandible: treatment with hyperbaric oxygen," Archives of Otolaryngology - Head and Neck Surgery, vol. 101, no. 3, pp. 173-177, 1975.

[60] Y. He, Z. Liu, Z. Tian, T. Dai, W. Qiu, and Z. Zhang, "Retrospective analysis of osteoradionecrosis of the mandible: proposing a novel clinical classification and staging system," International Journal of Oral and Maxillofacial Surgery, vol. 44, no. 12, pp. 1547-1557, 2015.

[61] D. Annane, J. Depondt, P. Aubert et al., "Hyperbaric oxygen therapy for radionecrosis of the jaw: a randomized, placebocontrolled, double-blind trial from the ORN96 study group," Journal of Clinical Oncology, vol. 22, no. 24, pp. 4893-4900, 2004.

[62] L. Forner, A. Berkowicz, E. Dickmeiss, O. Hyldegaard, E. C. Jansen, and A. Fischer-Nielsen, "Only minor stem cell mobilization in head and neck irradiated patients treated with hyperbaric oxygen," Diving and Hyperbaric Medicine Journal, vol. 49, no. 3, pp. 175-185, 2019.

[63] J. W. Denham and M. Hauer-Jensen, "The radiotherapeutic injury-a complex wound," Radiotherapy \& Oncology, vol. 63, no. 2, pp. 129-145, 2002.

[64] J. Xu, Z. Zheng, D. Fang et al., "Early-stage pathogenic sequence of jaw osteoradionecrosis in vivo," Journal of Dental Research, vol. 91, no. 7, pp. 702-708, 2012.

[65] S. L. Ruggiero, B. Mehrotra, T. J. Rosenberg, and S. L. Engroff, "Osteonecrosis of the jaws associated with the use of bisphosphonates: a review of 63 cases," Journal of Oral and Maxillofacial Surgery, vol. 62, no. 5, pp. 527-534, 2004.

[66] R. E. Marx, "Pamidronate (Aredia) and zoledronate (Zometa) induced avascular necrosis of the jaws: a growing epidemic," Journal of Oral and Maxillofacial Surgery, vol. 61, no. 9, pp. 1115-1117, 2003.

[67] J. Wang, N. M. Goodger, and M. A. Pogrel, "Osteonecrosis of the jaws associated with cancer chemotherapy," Journal of Oral and Maxillofacial Surgery, vol. 61, no. 9, pp. 1104-1107, 2003.

[68] R. Dambrain, "The pathogenesis of osteoradionecrosis," Rev Stomatol Chir Maxillofac, vol. 94, no. 3, pp. 140-147, 1993.

[69] J. Dhanda, D. Pasquier, L. Newman, and R. Shaw, "Current concepts in osteoradionecrosis after head and neck radiotherapy," Clinical Oncology, vol. 28, no. 7, pp. 459-466, 2016.

[70] Y. Chen, C. Zong, J. Jia et al., "A study on the protective effect of molecular hydrogen on osteoradionecrosis of the jaw in rats," International Journal of Oral and Maxillofacial Surgery, vol. 49, no. 12, pp. 1648-1654, 2020.

[71] J.-L. Lefaix and F. Daburon, "Diagnosis of acute localized irradiation lesions," Health Physics, vol. 75, no. 4, pp. 375-384, 1998.

[72] C. Madrid, M. Abarca, and K. Bouferrache, "Osteoradionecrosis: an update," Oral Oncology, vol. 46, no. 6, pp. 471-474, 2010.
[73] M. Martos-Fernández, M. Saez-Barba, J. López-López, A. Estrugo-Devesa, J. M. Balibrea-Del-Castillo, and C. Bescós-Atín, "Pentoxifylline, tocopherol, and clodronate for the treatment of mandibular osteoradionecrosis: a systematic review," Oral Surgery, Oral Medicine, Oral Pathology and Oral Radiology, vol. 125, no. 5, pp. 431-439, 2018.

[74] Z. Zhang, W. Xiao, J. Jia et al., "RETRACTED: the effect of combined application of pentoxifylline and vitamin $\mathrm{E}$ for the treatment of osteoradionecrosis of the jaws: a meta-analysis," Oral Surgery, Oral Medicine, Oral Pathology and Oral Radiology, vol. 129, no. 3, pp. 207-214, 2020.

[75] M. H. Seo, M. Y. Eo, H. Myoung, S. M. Kim, and J. H. Lee, "The effects of pentoxifylline and tocopherol in jaw osteomyelitis," Journal of the Korean Association of Oral and Maxillofacial Surgeons, vol. 46, no. 1, pp. 19-27, 2020.

[76] O. Breik, S. Tocaciu, K. Briggs, S. Tasfia Saief, and S. Richardson, "Is there a role for pentoxifylline and tocopherol in the management of advanced osteoradionecrosis of the jaws with pathological fractures? Case reports and review of the literature," International Journal of Oral and Maxillofacial Surgery, vol. 48, no. 8, pp. 1022-1027, 2019.

[77] S. J. Dixon, K. M. Lemberg, M. R. Lamprecht et al., "Ferroptosis: an iron-dependent form of nonapoptotic cell death," Cell, vol. 149, no. 5, pp. 1060-1072, 2012.

[78] R. Z. Yang, W. N. Xu, H. L. Zheng et al., "Involvement of oxidative stress-induced annulus fibrosus cell and nucleus pulposus cell ferroptosis in intervertebral disc degeneration pathogenesis," Journal of Cellular Physiology, vol. 236, no. 4, pp. 2725-2739, 2021

[79] M. Gao and X. Jiang, "To eat or not to eat - the metabolic flavor of ferroptosis," Current Opinion in Cell Biology, vol. 51, pp. 58-64, 2018.

[80] K. Hadian and B. R. Stockwell, "SnapShot: ferroptosis," Cell, vol. 181, no. 5, p. 1188, 2020.

[81] Y. Xie, W. Hou, X. Song et al., "Ferroptosis: process and function," Cell Death \& Differentiation, vol. 23, no. 3, pp. 369-379, 2016.

[82] G. Lei, Y. Zhang, P. Koppula et al., "The role of ferroptosis in ionizing radiation-induced cell death and tumor suppression," Cell Research, vol. 30, no. 2, pp. 146-162, 2020.

[83] L. F. Ye, K. R. Chaudhary, F. Zandkarimi et al., "Radiationinduced lipid peroxidation triggers ferroptosis and synergizes with ferroptosis inducers," ACS Chemical Biology, vol. 15, no. 2, pp. 469-484, 2020.

[84] R. Z. Yang, W.-N. Xu, H.-L. Zheng et al., "Exosomes derived from vascular endothelial cells antagonize glucocorticoidinduced osteoporosis by inhibiting ferritinophagy with resultant limited ferroptosis of osteoblasts," Journal of Cellular Physiology, vol. 236, no. 9, pp. 6691-6705, 2021.

[85] Y. He, C. Ma, J. Hou et al., "Chinese expert group consensus on diagnosis and clinical management of osteoradionecrosis of the mandible," International Journal of Oral and Maxillofacial Surgery, vol. 49, no. 3, pp. 411-419, 2020.

[86] S. P. Moubayed, B. L'Heureux-Lebeau, A. Christopoulos et al., "Osteocutaneous free flaps for mandibular reconstruction: systematic review of their frequency of use and a preliminary quality of life comparison," Journal of Laryngology \& Otology, vol. 128, no. 12, pp. 1034-1043, 2014.

[87] F. K. L. Spijkervet, M. T. Brennan, D. E. Peterson, M. J. H. Witjes, and A. Vissink, "Research frontiers in oral toxicities of cancer therapies: osteoradionecrosis of the jaws," Journal of the National Cancer Institute. Monographs, vol. 2019, no. 53, 2019. 
[88] A. Sultan, G. J. Hanna, D. N. Margalit et al., "The use of hyperbaric oxygen for the prevention and management of osteoradionecrosis of the jaw: a Dana-Farber/Brigham and women's cancer center multidisciplinary guideline," The Oncologist, vol. 22, no. 3, pp. 343-350, 2017.

[89] G. Laden, "Hyperbaric oxygen therapy for radionecrosis: clear advice from confusing data," Journal of Clinical Oncology, vol. 23, no. 19, p. 4465, 2005.

[90] A. J. Lyons and P. A. Brennan, "Pentoxifylline-a review of its use in osteoradionecrosis," British Journal of Oral and Maxillofacial Surgery, vol. 55, no. 3, pp. 230-234, 2017.

[91] M. Hayashi, M. Pellecer, E. Chung, and E. Sung, "The efficacy of pentoxifylline/tocopherol combination in the treatment of osteoradionecrosis," Special Care in Dentistry, vol. 35, no. 6, pp. 268-271, 2015.

[92] S. Delanian, C. Chatel, R. Porcher, J. Depondt, and J.-L. Lefaix, "Complete restoration of refractory mandibular osteoradionecrosis by prolonged treatment with a pentoxifylline-tocopherol-clodronate combination (PENTOCLO): a phase II trial," International Journal of Radiation Oncology, Biology, Physics, vol. 80, no. 3, pp. 832-839, 2011.

[93] S. Delanian, J. Depondt, and J.-L. Lefaix, "Major healing of refractory mandible osteoradionecrosis after treatment combining pentoxifylline and tocopherol: a phase II trial," Head \& Neck, vol. 27, no. 2, pp. 114-123, 2005.

[94] V. Patel, Y. Gadiwalla, I. Sassoon, C. Sproat, J. Kwok, and M. McGurk, "Use of pentoxifylline and tocopherol in the management of osteoradionecrosis," British Journal of Oral and Maxillofacial Surgery, vol. 54, no. 3, pp. 342-345, 2016.

[95] J. Dhanda, L. Rennie, and R. Shaw, "Current trends in the medical management of osteoradionecrosis using triple therapy," British Journal of Oral and Maxillofacial Surgery, vol. 56, no. 5, pp. 401-405, 2018.

[96] T. M. Karpiński and A. K. Szkaradkiewicz, "Chlorhexidinepharmaco-biological activity and application," European Review for Medical and Pharmacological Sciences, vol. 19, no. 7, pp. 1321-1326, 2015.

[97] B. R. Manzano, N. G. Santaella, M. A. Oliveira, C. M. F. Rubira, and P. S. d. S. Santos, "Retrospective study of osteoradionecrosis in the jaws of patients with head and neck cancer," Journal of the Korean Association of Oral and Maxillofacial Surgeons, vol. 45, no. 1, pp. 21-28, 2019.

[98] K. O'Dell and U. Sinha, "Osteoradionecrosis," Oral and Maxillofacial Surgery Clinics of North America, vol. 23, no. 3, pp. 455-464, 2011.

[99] P. N. Lambade, D. Lambade, and M. Goel, "Osteoradionecrosis of the mandible: a review," Oral and Maxillofacial Surgery, vol. 17, no. 4, pp. 243-249, 2013.

[100] Z. Zhou, M. Lang, W. Fan et al., "Prevention of osteoradionecrosis of the jaws by low-intensity ultrasound in the dog model," International Journal of Oral and Maxillofacial Surgery, vol. 45, no. 9, pp. 1170-1176, 2016.

[101] G. Gallesio, M. Del Fabbro, R. Pol, C. Mortellaro, and M. Mozzati, "Conservative treatment with plasma rich in growth factors-Endoret for osteoradionecrosis," Journal of Craniofacial Surgery, vol. 26, no. 3, pp. 731-736, 2015.

[102] I. G. Jin, J. H. Kim, H.-G. Wu, S. K. Kim, Y. Park, and S. J. Hwang, "Effect of bone marrow-derived stem cells and bone morphogenetic protein-2 on treatment of osteoradionecrosis in a rat model," Journal of Cranio-Maxillofacial Surgery, vol. 43, no. 8, pp. 1478-1486, 2015.

[103] G. Camolesi, K. Ortega, J. Medina et al., "Therapeutic alternatives in the management of osteoradionecrosis of the jaws. Systematic review," Medicina Oral, Patología Oral y Cirugía Bucal, vol. 26, no. 2, pp. e195-e207, 2021.

[104] J. D. Anderson, H. J. Johansson, C. S. Graham et al., "Comprehensive proteomic analysis of mesenchymal stem cell exosomes reveals modulation of angiogenesis via nuclear factor-KappaB signaling," Stem Cells, vol. 34, no. 3, pp. 601-613, 2016.

[105] V. Ulivi, R. Tasso, R. Cancedda, and F. Descalzi, "Mesenchymal stem cell paracrine activity is modulated by platelet lysate: induction of an inflammatory response and secretion of factors maintaining macrophages in a proinflammatory phenotype," Stem Cells and Development, vol. 23, no. 16, pp. 1858-1869, 2014.

[106] W. Liu, L. Li, Y. Rong et al., "Hypoxic mesenchymal stem cell-derived exosomes promote bone fracture healing by the transfer of miR-126," Acta Biomaterialia, vol. 103, pp. 196-212, 2020.

[107] T. Ma, Y. Chen, Y. Chen et al., "MicroRNA-132, delivered by mesenchymal stem cell-derived exosomes, promote angiogenesis in myocardial infarction," Stem Cells International, vol. 2018, Article ID 3290372, 11 pages, 2018.

[108] K. Yang, D. Li, M. Wang et al., "Exposure to blue light stimulates the proangiogenic capability of exosomes derived from human umbilical cord mesenchymal stem cells," Stem Cell Research \& Therapy, vol. 10, no. 1, p. 358, 2019.

[109] S. Hosseinpour, Y. He, A. Nanda, and Q. Ye, "MicroRNAs involved in the regulation of angiogenesis in bone regeneration," Calcified Tissue International, vol. 105, no. 3, pp. 223-238, 2019.

[110] S. Grosso, J. Doyen, S. K. Parks et al., "MiR-210 promotes a hypoxic phenotype and increases radioresistance in human lung cancer cell lines," Cell Death \& Disease, vol. 4, no. 3, p. e544, 2013.

[111] H. Gonzalez-King, N. A. García, I. Ontoria-Oviedo, M. Ciria, J. A. Montero, and P. Sepúlveda, "Hypoxia inducible factor$1 \alpha$ potentiates jagged 1-mediated angiogenesis by mesenchymal stem cell-derived exosomes," Stem Cells, vol. 35, no. 7, pp. 1747-1759, 2017.

[112] B. Liang, J.-M. Liang, J.-N. Ding, J. Xu, J.-G. Xu, and Y.-M. Chai, "Dimethyloxaloylglycine-stimulated human bone marrow mesenchymal stem cell-derived exosomes enhance bone regeneration through angiogenesis by targeting the AKT/mTOR pathway," Stem Cell Research \& Therapy, vol. 10, no. 1, p. 335, 2019.

[113] X. Liu, Q. Li, X. Niu et al., "Exosomes secreted from humaninduced pluripotent stem cell-derived mesenchymal stem cells prevent osteonecrosis of the femoral head by promoting angiogenesis," International Journal of Biological Sciences, vol. 13, no. 2, pp. 232-244, 2017.

[114] X. Qi, J. Zhang, H. Yuan et al., "Exosomes secreted by human-induced pluripotent stem cell-derived mesenchymal stem cells repair critical-sized bone defects through enhanced angiogenesis and osteogenesis in osteoporotic rats," International Journal of Biological Sciences, vol. 12, no. 7, pp. 836-849, 2016.

[115] J. D. McBride, L. Rodriguez-Menocal, W. Guzman, A. Candanedo, M. Garcia-Contreras, and E. V. Badiavas, "Bone marrow mesenchymal stem cell-derived CD63+ exosomes transport Wnt3a exteriorly and enhance dermal fibroblast proliferation, migration, and angiogenesis in vitro," Stem Cells and Development, vol. 26, no. 19, pp. 1384-1398, 2017.

[116] W. Du, K. Zhang, S. Zhang et al., "Enhanced proangiogenic potential of mesenchymal stem cell-derived exosomes 
stimulated by a nitric oxide releasing polymer," Biomaterials, vol. 133, pp. 70-81, 2017.

[117] L. Qian and J. Cen, "Hematopoietic stem cells and mesenchymal stromal cells in acute radiation syndrome," Oxidative Medicine and Cellular Longevity, vol. 2020, Article ID 8340756, 10 pages, 2020.

[118] M. Komaki, Y. Numata, C. Morioka et al., "Exosomes of human placenta-derived mesenchymal stem cells stimulate angiogenesis," Stem Cell Research \& Therapy, vol. 8, no. 1, p. 219, 2017.

[119] G. R. Willis, A. Fernandez-Gonzalez, J. Anastas et al., "Mesenchymal stromal cell exosomes ameliorate experimental bronchopulmonary dysplasia and restore lung function through macrophage immunomodulation," American Journal of Respiratory and Critical Care Medicine, vol. 197, no. 1, pp. 104-116, 2018.

[120] G. R. Willis, A. Fernandez-Gonzalez, M. Reis, S. A. Mitsialis, and S. Kourembanas, "Macrophage immunomodulation: the gatekeeper for mesenchymal stem cell derived-exosomes in pulmonary arterial hypertension?" International Journal of Molecular Sciences, vol. 19, no. 9, 2018.

[121] J. Shi, Y.-C. Zhao, Z.-F. Niu et al., "Mesenchymal stem cellderived small extracellular vesicles in the treatment of human diseases: progress and prospect," World Journal of Stem Cells, vol. 13, no. 1, pp. 49-63, 2021.

[122] C. R. Harrell, N. Jovicic, V. Djonov, N. Arsenijevic, and V. Volarevic, "Mesenchymal stem cell-derived exosomes and other extracellular vesicles as new remedies in the therapy of inflammatory diseases," Cells, vol. 8, no. 12, 2019.

[123] R. Domenis, A. Cifù, S. Quaglia et al., "Pro inflammatory stimuli enhance the immunosuppressive functions of adipose mesenchymal stem cells-derived exosomes," Scientific Reports, vol. 8, no. 1, Article ID 13325, 2018.

[124] C. Yunna, H. Mengru, W. Lei, and C. Weidong, "Macrophage M1/M2 polarization," European Journal of Pharmacology, vol. 877, Article ID 173090, 2020.

[125] A. Shapouri-Moghaddam, S. Mohammadian, H. Vazini et al., "Macrophage plasticity, polarization, and function in health and disease," Journal of Cellular Physiology, vol. 233, no. 9, pp. 6425-6440, 2018.

[126] P. Jiang, R. Liu, Y. Zheng et al., "MiR-34a inhibits lipopolysaccharide-induced inflammatory response through targeting Notch1 in murine macrophages," Experimental Cell Research, vol. 318, no. 10, pp. 1175-1184, 2012.

[127] W. Zilun, Q. Shuaihua, Z. Jinxuan, L. Yihai, L. Qiaoling, and W. Zhonghai, "Corrigendum to "miRNA-181a over-expression in mesenchymal stem cell-derived exosomes influenced inflammatory response after myocardial ischemia-reperfusion injury"," Life Sciences, vol. 232, Article ID 118045, 2019.

[128] Z. Wei, S. Qiao, J. Zhao et al., "miRNA-181a over-expression in mesenchymal stem cell-derived exosomes influenced inflammatory response after myocardial ischemia-reperfusion injury," Life Sciences, vol. 232, Article ID 116632, 2019.

[129] H. Liu, Z. Liang, F. Wang et al., "Exosomes from mesenchymal stromal cells reduce murine colonic inflammation via a macrophage-dependent mechanism," JCI Insight, vol. 4, no. 24, 2019.

[130] S. Biswas, G. Mandal, S. Roy Chowdhury et al., "Exosomes produced by mesenchymal stem cells drive differentiation of myeloid cells into immunosuppressive M2-polarized macrophages in breast cancer," The Journal of Immunology, vol. 203, no. 12, pp. 3447-3460, 2019.
[131] F. Wei, Z. Li, R. Crawford, Y. Xiao, and Y. Zhou, "Immunoregulatory role of exosomes derived from differentiating mesenchymal stromal cells on inflammation and osteogenesis," Journal of Tissue Engineering and Regenerative Medicine, vol. 13, no. 11, pp. 1978-1991, 2019.

[132] R. Zuo, M. Liu, Y. Wang et al., "BM-MSC-derived exosomes alleviate radiation-induced bone loss by restoring the function of recipient BM-MSCs and activating Wnt $/ \beta$-catenin signaling," Stem Cell Research \& Therapy, vol. 10, no. 1, p. 30, 2019.

[133] Y. Yang, Y.-C. Ye, Y. Chen et al., "Crosstalk between hepatic tumor cells and macrophages via $\mathrm{Wnt} / \beta$-catenin signaling promotes M2-like macrophage polarization and reinforces tumor malignant behaviors," Cell Death \& Disease, vol. 9, no. 8 , p. 793,2018

[134] S. A. Bloomfield, "Cellular and molecular mechanisms for the bone response to mechanical loading," International Journal of Sport Nutrition and Exercise Metabolism, vol. 11, no. Suppl, pp. S128-S136, 2001.

[135] M. Shahir, S. Mahmoud Hashemi, A. Asadirad et al., "Effect of mesenchymal stem cell-derived exosomes on the induction of mouse tolerogenic dendritic cells," Journal of Cellular Physiology, vol. 235, no. 10, pp. 7043-7055, 2020.

[136] M. Budoni, A. Fierabracci, R. Luciano, S. Petrini, V. Di Ciommo, and M. Muraca, "The immunosuppressive effect of mesenchymal stromal cells on B lymphocytes is mediated by membrane vesicles," Cell Transplantation, vol. 22, no. 2, pp. 369-379, 2013.

[137] L. Wang, Z. Gu, X. Zhao et al., "Extracellular vesicles released from human umbilical cord-derived mesenchymal stromal cells prevent life-threatening acute graft-versus-host disease in a mouse model of allogeneic hematopoietic stem cell transplantation," Stem Cells and Development, vol. 25, no. 24, pp. 1874-1883, 2016.

[138] M. Tofiño-Vian, "Microvesicles from human adipose tissuederived mesenchymal stem cells as a new protective strategy in osteoarthritic chondrocytes," International Journal of Experimental Cellular Physiology, Biochemistry, and Pharmacology, vol. 47, no. 1, pp. 11-25, 2018.

[139] L. A. Vonk, S. F. J. van Dooremalen, N. Liv et al., "Mesenchymal stromal/stem cell-derived extracellular vesicles promote human cartilage regeneration in vitro," Theranostics, vol. 8, no. 4, pp. 906-920, 2018.

[140] S. Cosenza, M. Ruiz, K. Toupet, C. Jorgensen, and D. Noël, "Mesenchymal stem cells derived exosomes and microparticles protect cartilage and bone from degradation in osteoarthritis," Scientific Reports, vol. 7, no. 1, Article ID 16214, 2017.

[141] A. Vallée, Y. Lecarpentier, R. Guillevin, and J. N. Vallée, "Interactions between TGF- $\beta 1$, canonical $\mathrm{WNT} / \beta$-catenin pathway and PPAR $\gamma$ in radiation-induced fibrosis," Oncotarget, vol. 8, no. 52, pp. 90579-90604, 2017.

[142] S. S. Nagaraja, U. Subramanian, and D. Nagarajan, "Radiation-induced $\mathrm{H} 3 \mathrm{~K} 9$ methylation on E-cadherin promoter mediated by ROS/Snail axis: role of G9a signaling during lung epithelial-mesenchymal transition," Toxicology in Vitro, vol. 70, Article ID 105037, 2021.

[143] X. Li, L. Duan, S. Yuan, X. Zhuang, T. Qiao, and J. He, "Ferroptosis inhibitor alleviates Radiation-induced lung fibrosis (RILF) via down-regulation of TGF- $\beta 1$," Journal of Inflammation, vol. 16, no. 1, p. 11, 2019.

[144] H. Kim, S.-H. Park, S. Y. Han, Y.-S. Lee, J. Cho, and J.-M. Kim, "LXA4-FPR2 signaling regulates radiation- 
induced pulmonary fibrosis via crosstalk with TGF- $\beta /$ Smad signaling," Cell Death \& Disease, vol. 11, no. 8, p. 653, 2020.

[145] L. Tian, "Myofibroblasts and their resistance to apoptosis: a possible mechanism of osteoradionecrosis," Clinical, Cosmetic and Investigational Dentistry, vol. 4, pp. 21-27, 2012.

[146] Q. Xu, Y. Cui, J. Luan, X. Zhou, H. Li, and J. Han, "Exosomes from $\mathrm{C} 2 \mathrm{C} 12$ myoblasts enhance osteogenic differentiation of MC3T3-E1 pre-osteoblasts by delivering miR-27a-3p," Biochemical and Biophysical Research Communications, vol. 498, no. 1, pp. 32-37, 2018.

[147] K. Kapinas, C. Kessler, T. Ricks, G. Gronowicz, and A. M. Delany, "miR-29 modulates Wnt signaling in human osteoblasts through a positive feedback loop," Journal of Biological Chemistry, vol. 285, no. 33, pp. 25221-25231, 2010.

[148] Y. Qin, L. Wang, Z. Gao, G. Chen, and C. Zhang, "Bone marrow stromal/stem cell-derived extracellular vesicles regulate osteoblast activity and differentiation in vitro and promote bone regeneration in vivo," Scientific Reports, vol. 6, no. 1, Article ID 21961, 2016.

[149] J.-F. Xu, G.-h. Yang, X.-H. Pan et al., “Altered microRNA expression profile in exosomes during osteogenic differentiation of human bone marrow-derived mesenchymal stem cells," PLoS One, vol. 9, no. 12, Article ID e114627, 2014.

[150] M. Zhang, S. Z. Yuan, H. Sun, L. Sun, D. Zhou, and J. Yan, "miR-199b-5p promoted chondrogenic differentiation of C3H10T1/2 cells by regulating JAG1," Journal of Tissue Engineering and Regenerative Medicine, vol. 14, no. 11, pp. 1618-1629, 2020.

[151] S. Huang, Y. Li, P. Wu et al., "microRNA-148a-3p in extracellular vesicles derived from bone marrow mesenchymal stem cells suppresses SMURF1 to prevent osteonecrosis of femoral head," Journal of Cellular and Molecular Medicine, vol. 24, no. 19, pp. 11512-11523, 2020.

[152] R. Wang, B. Xu, and H. Xu, "TGF- $\beta 1$ promoted chondrocyte proliferation by regulating Sp1 through MSC-exosomes derived miR-135b," Cell Cycle, vol. 17, no. 24, pp. 2756-2765, 2018.

[153] K. Gan, G.-h. Dong, N. Wang, and J.-f. Zhu, "miR-221-3p and miR-222-3p downregulation promoted osteogenic differentiation of bone marrow mesenchyme stem cells through IGF-1/ERK pathway under high glucose condition," Diabetes Research and Clinical Practice, vol. 167, Article ID 108121, 2020.

[154] B. Qu, J. He, Z. Zeng et al., "MiR-155 inhibition alleviates suppression of osteoblastic differentiation by high glucose and free fatty acids in human bone marrow stromal cells by upregulating SIRT1," Pfluegers Archiv European Journal of Physiology, vol. 472, no. 4, pp. 473-480, 2020.

[155] G. Tao, P. Mao, H. Guan et al., "Effect of miR-181a-3p on osteogenic differentiation of human bone marrow-derived mesenchymal stem cells by targeting BMP10," Artificial Cells, Nanomedicine, and Biotechnology, vol. 47, no. 1, pp. 4159-4164, 2019.

[156] J. Zou, J. Du, H. Tu et al., "Resveratrol benefits the lineage commitment of bone marrow mesenchymal stem cells into osteoblasts via miR-320c by targeting Runx2," Journal of Tissue Engineering and Regenerative Medicine, vol. 15, no. 4, pp. 347-360, 2021.

[157] G. Mao, Z. Zhang, S. Hu et al., "Exosomes derived from miR92a-3p-overexpressing human mesenchymal stem cells enhance chondrogenesis and suppress cartilage degradation via targeting WNT5A," Stem Cell Research \& Therapy, vol. 9, no. 1, p. 247, 2018.
[158] S.-C. Tao, T. Yuan, Y.-L. Zhang, W.-J. Yin, S.-C. Guo, and C.-Q. Zhang, "Exosomes derived from miR-140-5p-overexpressing human synovial mesenchymal stem cells enhance cartilage tissue regeneration and prevent osteoarthritis of the knee in a rat model," Theranostics, vol. 7, no. 1, pp. 180-195, 2017.

[159] E. Nemoto, Y. Ebe, S. Kanaya et al., "Wnt5a signaling is a substantial constituent in bone morphogenetic protein-2mediated osteoblastogenesis," Biochemical and Biophysical Research Communications, vol. 422, no. 4, pp. 627-632, 2012.

[160] P. Zhao, L. Xiao, J. Peng, Y. Q. Qian, and C. C. Huang, "Exosomes derived from bone marrow mesenchymal stem cells improve osteoporosis through promoting osteoblast proliferation via MAPK pathway," European Review for Medical and Pharmacological Sciences, vol. 22, no. 12, pp. 3962-3970, 2018.

[161] W. Liao, Y. Ning, H.-J. Xu et al., "BMSC-derived exosomes carrying microRNA-122-5p promote proliferation of osteoblasts in osteonecrosis of the femoral head," Clinical Science, vol. 133, no. 18, pp. 1955-1975, 2019.

[162] S. Wen, M. Dooner, Y. Cheng et al., "Mesenchymal stromal cell-derived extracellular vesicles rescue radiation damage to murine marrow hematopoietic cells," Leukemia, vol. 30, no. 11, pp. 2221-2231, 2016.

[163] M. Angelopoulou, E. Novelli, J. E. Grove et al., "Cotransplantation of human mesenchymal stem cells enhances human myelopoiesis and megakaryocytopoiesis in NOD/ SCID mice," Experimental Hematology, vol. 31, no. 5, pp. 413-420, 2003.

[164] T. Furuta, S. Miyaki, H. Ishitobi et al., "Mesenchymal stem cell-derived exosomes promote fracture healing in a mouse model," Stem Cells Translational Medicine, vol. 5, no. 12, pp. 1620-1630, 2016.

[165] C. W. Brown and A. M. Mercurio, "Ferroptosis resistance mediated by exosomal release of iron," Molecular \& Cellular Oncology, vol. 7, no. 3, Article ID 1730144, 2020.

[166] C. W. Brown, J. J. Amante, P. Chhoy et al., "Prominin2 drives ferroptosis resistance by stimulating iron export," Developmental Cell, vol. 51, no. 5, pp. 575-586, 2019.

[167] P. Strzyz, "Iron expulsion by exosomes drives ferroptosis resistance," Nature Reviews Molecular Cell Biology, vol. 21, no. 1, pp. 4-5, 2020.

[168] Y. Wang, Z. Wei, K. Pan, J. Li, and Q. Chen, “The function and mechanism of ferroptosis in cancer," Apoptosis: An International Journal on Programmed Cell Death, vol. 25, no. 11-12, pp. 786-798, 2020.

[169] J. Qin and Q. Xu, "Functions and application of exosomes," Acta Poloniae Pharmaceutica, vol. 71, no. 4, pp. 537-543, 2014.

[170] G. Kibria, E. K. Ramos, Y. Wan, D. R. Gius, and H. Liu, "Exosomes as a drug delivery system in cancer therapy: potential and challenges," Molecular Pharmaceutics, vol. 15, no. 9, pp. 3625-3633, 2018.

[171] V. de Araujo Farias, F. O’Valle, S. Serrano-Saenz et al., "Exosomes derived from mesenchymal stem cells enhance radiotherapy-induced cell death in tumor and metastatic tumor foci," Molecular Cancer, vol. 17, no. 1, p. 122, 2018.

[172] B. Malla, K. Zaugg, E. Vassella, D. M. Aebersold, and A. Dal Pra, "Exosomes and exosomal MicroRNAs in prostate cancer radiation therapy," International Journal of Radiation Oncology, Biology, Physics, vol. 98, no. 5, pp. 982-995, 2017.

[173] E. I. Azzam, S. M. de Toledo, T. Gooding, and J. B. Little, "Intercellular communication is involved in the bystander regulation of gene expression in human cells exposed to very 
low fluences of alpha particles," Radiation Research, vol. 150, no. 5, pp. 497-504, 1998.

[174] C. Mothersill and C. B. Seymour, "Cell-cell contact during gamma irradiation is not required to induce a bystander effect in normal human keratinocytes: evidence for release during irradiation of a signal controlling survival into the medium," Radiation Research, vol. 149, no. 3, pp. 256-262, 1998.

[175] S. Dutta, C. Warshall, C. Bandyopadhyay, D. Dutta, and B. Chandran, "Interactions between exosomes from breast cancer cells and primary mammary epithelial cells leads to generation of reactive oxygen species which induce DNA damage response, stabilization of p53 and autophagy in epithelial cells," PLoS One, vol. 9, no. 5, Article ID e97580, 2014.

[176] L. Mutschelknaus, C. Peters, K. Winkler et al., "Exosomes derived from squamous head and neck cancer promote cell survival after ionizing radiation," PLoS One, vol. 11, no. 3, Article ID e0152213, 2016.

[177] T. B. Steinbichler, J. Dudás, S. Skvortsov, U. Ganswindt, H. Riechelmann, and I.-I. Skvortsova, "Therapy resistance mediated by exosomes," Molecular Cancer, vol. 18, no. 1, p. 58, 2019.

[178] D. Nolen, S. B. Cannady, M. K. Wax et al., "Comparison of complications in free flap reconstruction for osteoradionecrosis in patients with or without hyperbaric oxygen therapy," Head \& Neck, vol. 36, no. 12, pp. 1701-1704, 2014.

[179] K. Aitasalo, J. Niinikoski, R. Grénman, and E. Virolainen, “A modified protocol for early treatment of osteomyelitis and osteoradionecrosis of the mandible," Head \& Neck, vol. 20, no. 5, pp. 411-417, 1998.

[180] A. T. T. Wong, S. Y. Lai, G. B. Gunn et al., "Symptom burden and dysphagia associated with osteoradionecrosis in longterm oropharynx cancer survivors: a cohort analysis," Oral Oncology, vol. 66, pp. 75-80, 2017.

[181] R. J. Simpson, S. S. Jensen, and J. W. E. Lim, "Proteomic profiling of exosomes: current perspectives," Proteomics, vol. 8, no. 19, pp. 4083-4099, 2008.

[182] F. Fleissner, Y. Goerzig, A. Haverich, and T. Thum, "Microvesicles as novel biomarkers and therapeutic targets in transplantation medicine," American Journal of Transplantation, vol. 12, no. 2, pp. 289-297, 2012.

[183] Y. Li, L. Fan, S. Liu et al., "The promotion of bone regeneration through positive regulation of angiogenic-osteogenic coupling using microRNA-26a," Biomaterials, vol. 34, no. 21, pp. 5048-5058, 2013

[184] C. Lässer, M. Eldh, and J. Lötvall, "Isolation and characterization of RNA-containing exosomes," Journal of Visualized Experiments: Journal of Visualized Experiments, vol. 59, Article ID e3037, 2012.

[185] A. Abramowicz, W. Łabaj, J. Mika et al., "MicroRNA profile of exosomes and parental cells is differently affected by ionizing radiation," Radiation Research, vol. 194, no. 2, pp. 133-142, 2020.

[186] B. Mateescu, E. J. K. Kowal, B. W. M. van Balkom et al., "Obstacles and opportunities in the functional analysis of extracellular vesicle RNA-an ISEV position paper," Journal of Extracellular Vesicles, vol. 6, no. 1, Article ID 1286095, 2017.

[187] R. A. Haraszti, R. Miller, M. Stoppato et al., "Exosomes produced from 3D cultures of MSCs by tangential flow filtration show higher yield and improved activity," Molecular Therapy, vol. 26, no. 12, pp. 2838-2847, 2018.
[188] C. Soekmadji, A. F. Hill, M. H. Wauben et al., "Towards mechanisms and standardization in extracellular vesicle and extracellular RNA studies: results of a worldwide survey," Journal of Extracellular Vesicles, vol. 7, no. 1, Article ID 1535745, 2018. 